\title{
Beoordeling van coassistenten in de kliniek: nog altijd ruimte ter verbetering
}

\author{
M. Buiten, R. Walhout, M. Heeren, namens het KNMG Studentenplatform*
}

\section{Samenvatting}

Inleiding: Beoordelingen van coschappen zijn belangrijk voor het leerproces van de coassistent. De kwaliteit van de beoordeling wordt door coassistenten echter regelmatig ter discussie gesteld. Het KNMG Studentenplatform onderzocht of coassistenten tevreden zijn over de huidige wijze van beoordelen en wat volgens hen de kenmerken van een goede beoordeling zijn.

Methode: In december 2008 werden alle studentleden van de KNMG persoonlijk benaderd met een digitale enquête $(n=10.504)$. In de enquête werden zes meerkeuzevragen gesteld over de mate van tevredenheid en over de kenmerken van een goede beoordeling tijdens de coschappen. Indien van toepassing werd naar de redenen voor de ontevredenheid gevraagd.

Resultaten: 2460 studenten geneeskunde hebben de enquête ingevuld (responspercentage 23,4\%). Het responsprofiel komt overeen met dat van studenten geneeskunde in Nederland. Van de respondenten loopt $42 \%(n=1046)$ coschappen waarvan $72 \%$ neutraal of tevreden is over de kwaliteit van de beoordelingen en $28 \%$ ontevreden. De meest genoemde kenmerken van een goede beoordeling zijn: feedback met opbouwend commentaar en aandacht voor alle facetten van het functioneren en observatie van de coassistent in de praktijk. De voornaamste redenen voor ontevredenheid zijn: te weinig observatie door de beoordelaar, onvoldoende feedback en een slechte overeenstemming van de beoordeling met de geleverde prestaties.

Discussie en conclusie: Hoewel meer dan de helft van de coassistenten (72\%) tevreden of neutraal is over de beoordeling, is een aanzienlijk deel (28\%) echter nog ontevreden. Zij vinden dat feedback en observatie in de praktijk de voornaamste kenmerken van een goede beoordeling zijn. Bij de beoordeling dienen volgens hen alle facetten van het functioneren aan de orde te komen. Omdat de beoordeling een essentiële driffveer is in het leerproces van studenten, moet er meer aandacht besteed worden aan de kwaliteit van deze beoordeling. (Buiten M, Walhout R, Heeren M. Beoordeling van coassistenten in de kliniek: nog altijd ruimte ter verbetering. Tijdschrift voor Medisch Onderwijs 2010;29(4):229-236.)

\section{Inleiding}

Gedurende de studie geneeskunde verwerft de student steeds meer competenties. Het gaat hierbij niet alleen om medische kennis, maar ook om bijvoorbeeld communicatievaardigheden, professioneel gedrag en medisch technisch handelen. ${ }^{1}$ Kennis kan getoetst worden door middel van mondelinge of schriftelijke toetsen. Het portfolio, de zelfreflectie en het 'peerassessment' kunnen worden gebruikt om professionaliteit te beoordelen. ${ }^{2-4}$ In het

\footnotetext{
* Het KNMG Studentenplatform is een landelijke en onafhankelijke belangenbehartiger van studenten geneeskunde. Het platform houdt zich bezig met maatschappelijke en onderwijskundige onderwerpen die studenten geneeskunde in heel Nederland aangaan en die de lokale situatie op de medische faculteiten overstijgen. De standpunten van het KNMG Studentenplatform worden zoveel mogelijk gebaseerd op representatief (opinie)onderzoek (www.knmgstudentenplatform.nl)
} 
begin van de studie verwerft de student voornamelijk kennis die tijdens de coschappen in de praktijk wordt toegepast. Daar er geen methode voor handen is waarmee alle competenties in de klinische fase tegelijkertijd beoordeeld kunnen wor$\operatorname{den}^{5-6}$ zullen diverse beoordelingsmethoden gehanteerd moeten worden. Alleen op deze manier kan de validiteit van de beoordeling gewaarborgd blijven. ${ }^{7-8}$

Toetsing is een essentiële drijfveer in het leerproces van studenten. Studenten die tevreden zijn over de kwaliteit van de beoordeling zijn gemotiveerder en halen meer rendement uit hun studie. ${ }^{9} \mathrm{De}$ beoordeling van coassistenten is daarom een belangrijk onderdeel van de opleiding.

Iedere medische faculteit heeft haar eigen wijze om coassistenten te beoordelen. Wel zijn er een aantal overeenkomsten. Zo worden coassistenten op meerdere vaardigheden beoordeeld. Onder andere zijn medische kennis, anamnese, klinische vaardigheden, statusvoering en professionaliteit belangrijk. Een relatief nieuwe methode om dit alles te toetsen is het verzamelen van korte praktijkbeoordelingen, zodat er een totaalbeeld van het functioneren in de praktijk wordt gevormd. Zonder uitzondering wordt deze korte praktijkbeoordeling inmiddels op alle medische faculteiten gehanteerd. Over het algemeen wordt de beoordeling door een staflid verricht.

Er zijn echter ook verschillen aan te wijzen. In Maastricht en Nijmegen krijgen de studenten zowel een beoordeling in de kliniek als een mondeling examen op de faculteit. Groningse en Rotterdamse studenten houden tijdens hun coschap een logboek bij en bij sommige opleidingen wordt in het eindoordeel het cijfer van een schriftelijke toets meegenomen. Naast de verschillen tussen de opleidingen zijn er soms ook verschillen binnen de opleiding omdat op de afdelingen niet altijd op uniforme wijze beoordeeld wordt. En ten slotte heeft ieder staflid weer een eigen stijl in de wijze van beoordelen, wat kan leiden tot verschillende beoordelingen binnen het coschap.

In 2002 werd aangetoond dat de coassistenten niet tevreden waren over de kwaliteit van de beoordeling. De conclusie was dat er onvoldoende gebruik gemaakt werd van de motiverende en sturende invloed van een beoordeling. ${ }^{10}$ Het verbeteren van de klinische beoordeling dient te gebeuren door het optimaliseren van de universele factoren. Om te achterhalen of de beoordeling in de ogen van de huidige coassistenten nog verbetering behoeft, deed het KNMG Studentenplatform onderzoek. Er werd onderzocht in hoeverre coassistenten tevreden zijn over de huidige kwaliteit van beoordelen en wat volgens hen kenmerken van een goede beoordeling zijn. De ontevreden coassistenten werd tevens gevraagd naar de redenen voor onvrede.

\section{Methode}

Het studentenplatform van de KNMG houdt ieder jaar een enquête onder zijn studenten om de mening van de achterban te peilen over actuele onderwerpen. Nadat de enquête ter beoordeling was voorgelegd aan een testpanel $(n=30)$ om onduidelijkheden en onjuistheden in de vraagstelling en antwoordcategorieën te achterhalen, werd de enquête in november 2008 online verspreid onder alle studentleden van de KNMG, gevolgd door een persoonlijke uitnodiging via e-mail in de periode november/december 2008. In de enquête werd gevraagd naar hun mening over verschillende onderwerpen. De enquête kon per persoon één keer ingevuld worden. Er werd tweemaal een herinnering gestuurd naar non-respondenten. 
In totaal hebben 10.504 KNMG-studentleden een uitnodiging ontvangen om deel te nemen aan het onderzoek. Hiervan hebben in totaal 2460 respondenten de gehele vragenlijst ingevuld (74\% vrouw, $26 \%$ man). Dit komt neer op een responspercentage van $23,4 \%$. Het profiel van de respondenten komt overeen met dat van de totale populatie studenten geneeskunde wat betreft geslacht, faculteit en studiejaar. $43 \%$ van de respondenten $(n=1046)$ gaf aan coschappen te lopen of te hebben gelopen. Van de respondenten uit Maastricht en Utrecht was dit percentage significant hoger (54\% respectievelijk $60 \%$ ). Van de groep coassistenten had $60 \%$ meer dan zes coschappen gelopen.

\section{Beoordeling tijdens de klinische fase}

In de enquête zijn zes meerkeuzevragen opgenomen over de beoordeling tijdens de klinische fase. Deze vragen werden alleen gesteld aan coassistenten. Aan hen werd allereerst gevraagd hoeveel coschappen ze hadden gelopen. Daarna werd gevraagd om op een vijfpuntsschaal hun tevredenheid aan te geven over de manier van beoordelen. Om te achterhalen welke kenmerken coassistenten belangrijk vinden in de beoordeling van een coschap, is hen een aantal keuzemogelijkheden voorgelegd (zie Box 1). De respondenten konden maximaal vier kenmerken aangeven die zij belangrijk vonden. Indien een respondent ontevreden was, werd gevraagd naar de redenen van de ontevredenheid (zie Box 2). De respondent kon hier meerdere antwoorden kiezen en ook alternatieve redenen aandragen. Met behulp van een chi-kwadraat $\left(\chi^{2}\right)$ toets werd onderzocht of de variabelen geslacht, studiejaar en faculteit van invloed waren op de antwoorden op bovengenoemde vragen. Hierbij werd een significantieniveau van 0.05 gehanteerd.
Box 1. Wat zijn de belangrijkste voorwaarden waaraan een goede coschapbeoordeling volgens jou moet voldoen? (maximaal vier antwoorden mogelijk).

- Feedback met opbouwend commentaar

- Tussenbeoordeling voorafgaand aan eindbeoordeling

- Gelijke beoordelingscriteria voor elke coassistent

- Aandacht voor alle facetten van het functioneren tijdens een coschap (bijvoorbeeld kennis, vaardigheden, professionaliteit)

- Observatie van de coassistent in de praktijk

- Ervaren en deskundige beoordelaar

- Meer dan één beoordelaar

- Beoordelingscriteria zijn vooraf bekend

- Beoordeling gebaseerd op verschillende toetsingsvormen (bijvoorbeeld portfolio, examen patiënt)

- Coassistent wordt op zijn gemak gesteld

- Anders, namelijk: ...

Box 2. Wat is de reden dat je ontevreden bent over de manier waarop jouw coschappen beoordeeld zijn (meerdere antwoorden mogelijk).

- Mijn beoordeling was niet in verhouding tot mijn geleverde prestaties

- Ik werd beoordeeld op niet-relevante criteria

- De beoordelaar heeft mij onvoldoende gezien tijdens het coschap

- Ik kreeg te weinig concrete feedback van de beoordelaar

- De criteria waarop ik beoordeeld werd waren van tevoren niet bekend

- Anders, namelijk: ... 


\section{Resultaten}

Het item tevredenheid over de kwaliteit van de beoordeling van coschappen werd door 1040 respondenten gescoord. 47\% van de respondenten is tevreden tot zeer tevreden over de beoordeling van de coschappen (zie Figuur 1); 28\% van de respondenten $(\mathrm{n}=287)$ is hierover ontevreden tot zeer ontevreden.

\section{Kenmerken van een goede beoordeling}

Respondenten gaven aan de volgende kenmerken het belangrijkst te vinden bij de beoordeling van een coschap (zie Figuur 2): feedback met opbouwend commentaar, aandacht voor alle facetten van het functioneren in de kliniek en observatie van de coassistent in de praktijk. Respondenten van de opleidingen in Groningen, Amsterdam (UvA), Leiden en Utrecht gaven significant vaker aan dat feedback met opbouwend commentaar een belangrijke voorwaarde is voor de beoordeling. Respondenten van de opleidingen in Rotterdam en Nijmegen vonden aandacht voor alle facetten van het functioneren tijdens een coschap juist belangrijker. Observatie van de coassistent in de praktijk werd vooral door de Groningse en Maastrichtse respondenten aangemerkt als een belangrijk kenmerk van een goede beoordeling.

Kundigheid van de beoordelaar, beoordeling op basis van meerdere toetsingsvormen, beoordelingscriteria die van tevoren bekend zijn, of het op gemak gesteld worden tijdens de beoordeling, werden door de respondenten minder vaak belangrijk gevonden.

\section{Redenen voor ontevredenheid}

Onvoldoende observatie door de beoordelaar in de kliniek was de meest genoemde reden voor ontevredenheid. Andere redenen voor ontevredenheid waren onvoldoende concrete feedback en de hoogte van het cijfer in verhouding tot de geleverde prestaties (zie Figuur 3). Respondenten van de opleidingen in Groningen, Leiden en Utrecht gaven het vaakst aan dat zij te weinig concrete feedback ontvingen van hun beoordelaar. Dit in tegenstelling tot de Nijmeegse en Maastrichtse respondenten.

\section{Discussie}

Het responspercentage van de enquête bedroeg $23,4 \%$. Uitgaande van ongeveer 5000 coassistenten in Nederland heeft een vijfde ( $n=1046)$ van hen de enquête ingevuld. Het profiel van de respondenten komt overeen met dat van de Nederlandse student geneeskunde. De kans op selectiebias is laag omdat het KNMG lidmaatschap al meer dan zes jaar gratis is en de meeste studenten lid worden in de introductietijd. De enquête kon per persoon slechts één maal worden ingevuld. Daarnaast werden in de enquête niet alleen vragen gesteld over de beoordeling van de coschappen, maar ook over andere onderwerpen. Het significant hogere aantal respondenten uit Utrecht is te verklaren door-

Tevredenheid beoordeling coschap

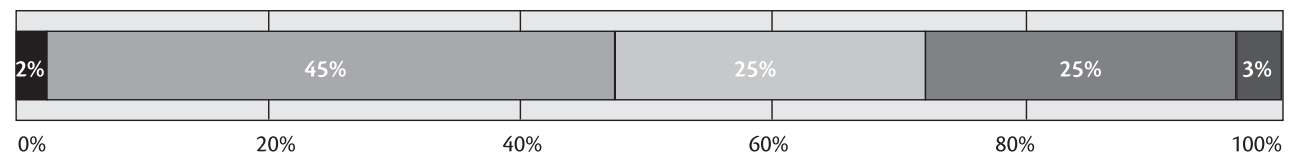

basis = coassistent, op respons

$\mathrm{n}=1.040$

Zeer tevreden $\square$ Tevreden

Neutraal

Ontevreden

Helemaal ontevreden

Figuur 1. Tevredenheid van coassistenten over de manier van beoordelen tijdens coschappen. 
Feedback met opbouwend commentaar

Aandacht voor alle facetten van het functioneren tijdens een coschap

Observatie van de coassistent in de praktijk

Gelijke beoordelingscriteria voor elke coassistent

Tussenbeoordeling voorafgaand aan eindbeoordeling

Meer dan één beoordelaar

Ervaren en deskundige beoordelaar

Beoordeling gebaseerd op verschilllende toetsingsvormen

Beoordelingscriteria zijn vooraf bekend

Coassistent wordt op zijn gemak gesteld

Anders

basis $=$ coassistent, $\mathrm{n}=1.040$

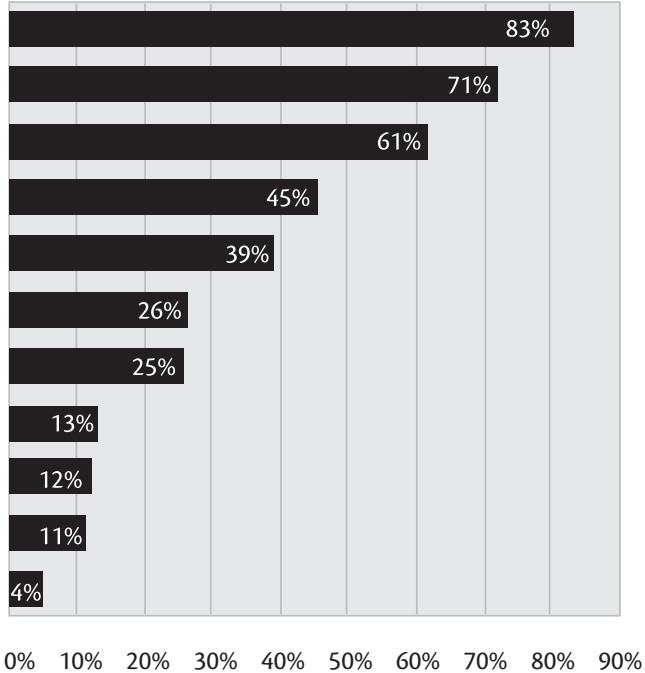

Figuur 2. Kenmerken van een goede beoordeling van coschappen volgens coassistenten.

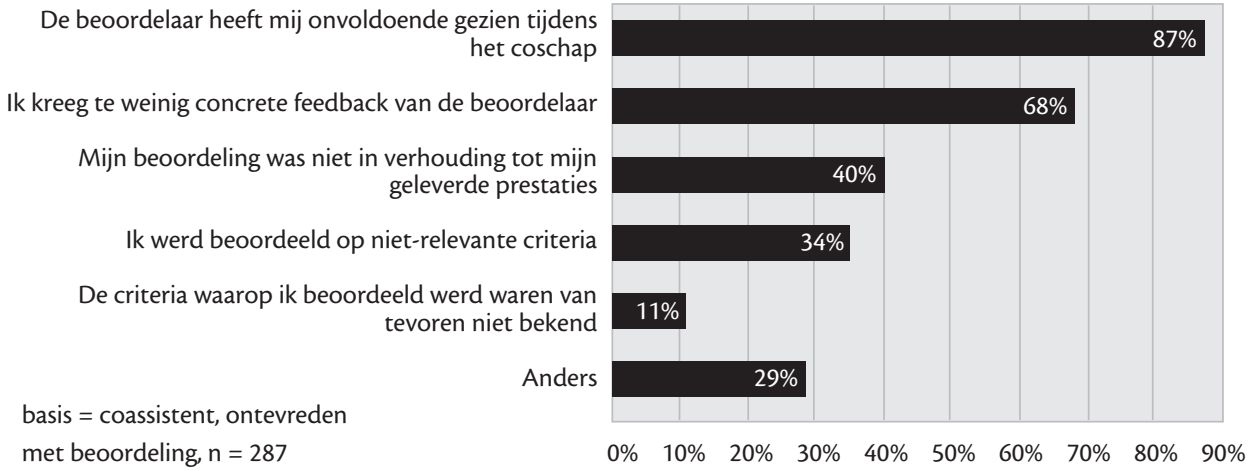

Figuur 3. Redenen voor ontevredenheid over de beoordeling van het coschap.

dat de coschappen in Utrecht al in het derde jaar aanvangen; voor het relatief hoge aantal respondenten uit Maastricht hebben we geen verklaring.

In 2002 werd aangetoond dat coassistenten niet tevreden waren over de kwaliteit van de beoordeling. ${ }^{10}$ Alhoewel een groot deel van de coassistenten momenteel wel tevreden $(47 \%)$ of neutraal $(25 \%)$ is over de kwaliteit van beoordelen tijdens de coschappen, is uit de enquête gebleken dat $28 \%$ van de coassistenten echter nog steeds ontevreden is. De nieuwe resultaten laten zien dat er nog altijd ruimte is voor verbetering. In de rest van dit artikel zullen handvatten gegeven worden om deze verbetering te bewerkstelligen (zie Box 3 ).

Gebrek aan observatie door de beoordelaar is de meest genoemde reden voor ontevredenheid (87\%). Medisch specialisten 
vinden het verwerven van klinische vaardigheden een belangrijk onderdeel van de coschappen. ${ }^{11}$ Een representatieve beoordeling van deze vaardigheden is echter niet mogelijk zonder de coassistent in de praktijk bezig te zien. ${ }^{12} \mathrm{Om}$ tot een betrouwbaar eindoordeel van een student te komen, moet deze meerdere malen beoordeeld worden. ${ }^{13}$ Bij gebrek aan voldoende observatie is de beoordelaar niet in staat een weloverwogen cijfer te geven dat recht doet aan het functioneren van de coassistent. Goede inzet en prestatie blijven hierdoor soms onbeloond. Bovendien kan niet worden gesignaleerd welke coassistenten onvoldoende functioneren, waardoor passende maatregelen en ondersteuning uitblijven. ${ }^{14}$ Het is dus een belangrijke verantwoordelijkheid van de beoordelaar om zorg te dragen voor voldoende observatie van de coassistent. Korte klinische beoordelingen maken een gerichte observatie mogelijk.

Bij de ontevreden studenten is gebrek aan feedback voor $68 \%$ reden voor onvrede. Ruim vier op de vijf coassistenten (83\%) noemt feedback met (opbouwend) commentaar een wezenlijk onderdeel voor de beoordeling. Het krijgen van goede feedback is daarbij belangrijker dan de positieve inhoud van het commentaar. Een beoordeling op basis van getoonde vaardigheden is alleen van educatieve waarde wanneer deze onderbouwd wordt. ${ }^{12}{ }^{15} \mathrm{Be}$ oordelaars dienen de beoordeling daarom te benaderen als middel tot leren en niet als doel op zich.

Feedback kan gegeven worden volgens de Pendleton rules. ${ }^{15}$ Eerst wordt de coassistent gevraagd wat in zijn optiek goed ging, waarna de beoordelaar dit eveneens aangeeft. Op dezelfde wijze wordt de kritiek besproken. De achterliggende gedachte is dat door het combineren van complimenten met kritiek het rendement van de reflectie verhoogd wordt. ${ }^{11}$ Wan- neer adequate feedback ontbreekt wordt voorbijgegaan aan het uiteindelijke doel van een beoordeling, namelijk de kennis over het eigen functioneren verbeteren en daarmee de coassistent naar een hoger niveau brengen. De beoordelaar dient de feedback bij voorkeur op gezette tijdstippen te geven, zodat een goed beeld van de voortgang wordt gevormd. ${ }^{16}$ De verantwoordelijkheid voor feedback ligt hierbij niet alleen bij de beoordelaar. Om meer inzicht in zijn eigen functioneren te krijgen, hoort de coassistent ook zelf om feedback te vragen.

Een andere reden voor ontevredenheid is dat de eindbeoordeling niet in verhouding staat tot de geleverde prestaties. Een mogelijke verklaring hiervoor kan zijn dat de coassistent op andere aspecten wordt beoordeeld dan verwacht. In de opmerkingen gaven coassistenten frequent aan dat zij getoetst werden op kennis en minder op prestaties. Functioneren in de kliniek kan echter niet met theoretische toetsen beoordeeld worden. ${ }^{11}$ In de eindbeoordeling dienen alle competenties aan bod te komen. Een andere oorzaak van de discrepantie tussen de eindbeoordeling en de geleverde prestaties kan, zoals eerder genoemd, liggen in een gebrek aan observatie in de praktijk.

Box 3. Aanbevelingen voor de beoordeling van coassistenten in de kliniek.

- Meer observatie in de praktijk met behulp van korte klinische beoordelingen

- Feedback op gezette tijdstippen in het coschap (volgens de Pendleton rules)

- De eindbeoordeling dient een optelsom te zijn van alle te toetsen competenties (zowel kennis, als vaardigheden en professioneel gedrag) 


\section{Conclusie}

Hoewel meer dan de helft van de coassistenten $(72 \%)$ tevreden of neutraal is over de beoordeling, is een aanzienlijk deel $(28 \%)$ nog ontevreden. Bij de beoordeling dienen volgens hen alle facetten van het functioneren aan de orde te komen. Feedback en observatie in de praktijk zijn volgens coassistenten de voornaamste factoren bij de totstandkoming van een goede beoordeling. Omdat de beoordeling een essentiële drijfveer is in het leerproces van studenten, dient meer aandacht besteed te worden aan de kwaliteit van deze beoordeling.

\section{Literatuur}

1. Herwaarden CLA van, Laan RFJM, Leunissen RRM. Raamplan artsenopleiding 2009. Utrecht: Nederlandse Federatie van Universitaire Medische Centra; 2009. [The 2009 Framework for undergraduate medical education in the Netherlands. Dutch Federation of University Medical Centres; 2009].

2. Snadden D. Portfolios- attempting to measure the unmeasurable? Med Educ 1999;33(7):478-479.

3. Dochy F, Segers M, Sluijsmans D. The use of self, peer and co-assessment in higher education: a review. Higher Educ 1999;24:331-350.

4. Lockyer J. Multisource feedback in the assessment of physician competencies. J Contin Educ Health Prof 2003;23(1):4-12.

5. Miller GE. The assessment of clinical skills/competence/performance. Acad Med 1990;65:S63-67.

6. Vleuten CP van der, Schuwirth LW. Assessing professional competence: from methods to programmes. Med Educ 2005;39:309-17.

7. Neufeld VR, Norman GR. Assessing clinical competence. New York: Springer Publishing Company; 1985.

8. Wass V, Vleuten C van der, Shatzer J, Jones R. Assessment of clinical competence. Lancet 2001; 357(2960):945-949.

9. Cross Shepard LA. The role of assessment in a learning culture. Educational Researcher 2000; 29:4-14.

10. Dijk N van, Penders GBS, Dam SC van, namens het Landelijk Overleg Co-assistenten (LOCA). Beoordeling tijdens de co-assistentschappen; verslag van een discussie door co-assistenten. Tijdschrift voor Medisch Onderwijs 2002; 21(6):267-273. [For the national Forum of Clinical Clerks (LOCA). Clerkship assessment; the outcome of discussions among students. Netherlands Journal of Medical Education 2003;21(6):267-273.

11. Sargeant JM, Mann KV, Vleuten CP van der, Metsemakers JF. Reflection: a link between receiving and using assessment feedback. Adv Health Sci Educ Theory Pract 2009;14(3):399-410.

12. Gordon J. ABC of learning and teaching in medicine: One to one teaching and feedback. BMJ 2003:326(7388);543-545.

13. Lohuizen MT van, Kuks JBM, Hell EA van, Stewart RE, Cohen-Schotanus J. Longitudinale klinische beoordelingen en competentiegroei: een betrouwbaarheidsstudie (abstract). Tijdschrift voor Medisch Onderwijs 2009;28(1):44-45. [Logitudinal clinical assessment and competence growth: a reliability study (abstract). Netherlands Journal of Medical Education 2009;28(1):44-45].

14. Rynja S, Cents R, Morsink M. Tabee lomperiken en horken. Med Contact 2007;62:73-75. [Bye Bye louts and boors. Medical Contact 2007;62:73-75].

15. Pendleton D, Scofield T, Tate P, Havelock P. The consultation: an approach to learning and teaching. Oxford: Oxford University Press; 1984.

16. Dolmans DHJM, Wolfhagen IHAP, Heineman E, Scherpbier AJJA. Factors Adversely Affecting Student Learning in the Clinical Learning Environment: A Student Perspective. Educ Health 2008;21(3):32.

\section{De auteurs:}

Maurits Buiten, student geneeskunde, UMC Groningen. *

Renée Walhout, student geneeskunde, UMC Utrecht.*

Monique Heeren, student geneeskunde (thans afgestudeerd), UMC St. Radboud Nijmegen.*

* Allen waren ten tijde van het onderzoek lid van het KNMG Studentenplatform.

Correspondentieadres:

KNMG, t.a.v. Studentenplatform, postbus 20051,3502

LB Utrecht. Tel.: 030-2823322; e-mail:

secretarisstudentenplatform@fed.knmg.nl

Belangenconflict: geen gemeld

Financiële ondersteuning: geen gemeld 


\section{Summary}

Introduction: Clerkship assessment is important to stimulate the learning of students, but the quality of clerkship assessment is often criticised by students. The Student Board of the Royal Dutch Medical Association (KNMG) examined students' satisfaction with the quality of this type of assessment.

Method: A digital questionnaire was sent to all 10,504 student members of KNMG in December 2008. The questionnaire consisted of six multiple choice questions about students' satisfaction with clerkship assessment and the characteristics of good clerkship assessment. If students expressed dissatisfaction, they were asked to explain why they were dissatisfied.

Results: 2,460 medical students completed the questionnaire (23.4\%). The response profile matched the general profile of medical students in the Netherlands. $42 \%$ of the respondents were undertaking clinical clerkships $(n=1,046)$. Of these students, $72 \%$ indicated satisfaction with or a neutral judgement of the quality of assessments, while $28 \%$ indicated dissatisfaction. The main characteristics of good assessment mentioned by the students were: constructive feedback, attention to all aspects of a student's performance and observation of students during clinical activities. The most frequently mentioned reasons for dissatisfaction were: lack of observation by supervisors, inadequate feedback and poor agreement between grades and performance.

Discussion and conclusion: Although more than 50\% of the respondents with clerkship experience were satisfied with clerkship assessments, a considerable percentage (28\%) expressed dissatisfaction. Constructive feedback and observation are considered important features of good assessment. Assessment should also cover all aspects of students' performance during clerkships. Since assessment is an essential drive for student learning, it is essential that more attention should be paid to assessment quality. (Buiten M, Walhout R, Heeren M. Clerkship assessment: still room for improvement. Netherlands Journal of Medical Education 2010;29(4):229-236.) 